Article

\title{
On-Chip Isoniazid Exposure of Mycobacterium smegmatis Penicillin-Binding Protein (PBP) Mutant Using Time-Lapse Fluorescent Microscopy
}

\author{
Meltem Elitas \\ Faculty of Engineering and Natural Sciences, Sabanci University, Tuzla, 34956 Istanbul, Turkey; \\ melitas@sabanciuniv.edu; Tel.: +90-538-810-2930
}

Received: 30 September 2018; Accepted: 27 October 2018; Published: 31 October 2018

\begin{abstract}
Antibiotic resistance has been one of the biggest threats to global health. Despite the available prevention and control strategies and efforts in developing new antibiotics, the need remains for effective approaches against antibiotic resistance. Efficient strategies to cope with antimicrobial resistance require a quantitative and deeper understanding of microbial behavior, which can be obtained using different techniques to provide the missing pieces of the current antibiotic-resistance puzzle. Microfluidic-microscopy techniques are among the most promising methods that contribute modernization of traditional assays in microbiology. They provide monitoring and manipulation of cells at micro-scale volumes. Here, we combined population-level, culture-based assays with single-cell resolution, microfluidic-microscopy systems to investigate isoniazid response of Mycobacterium smegmatis penicillin-binding protein (PBP) mutant. This mutant exhibited normal growth in plain medium and sensitivity to stress responses when treated with thermal stress $\left(45^{\circ} \mathrm{C}\right)$, detergent stress ( $0.1 \%$ sodium dodecyl sulfate), acid stress ( $\mathrm{pH} 4.5)$, and nutrient starvation (1XPBS). The impact of msm0031 transposon insertion on drug-mediated killing was determined for isoniazid (INH, $50 \mu \mathrm{g} / \mathrm{mL}$ ), rifampicin (RIF, $200 \mu \mathrm{g} / \mathrm{mL}$ ), ethionamide (ETH, $200 \mu \mathrm{g} / \mathrm{mL}$ ), and ethambutol $(\mathrm{EMB}, 5 \mu \mathrm{g} / \mathrm{mL}$ ). The PBP mutant demonstrated remarkable isoniazid-killing phenotype in batch culture. Therefore, we hypothesized that single-cell analysis will show increased lysis kinetics and fewer intact cells after drug treatment. However, the single-cell analysis data showed that upon isoniazid exposure, the percentage of the intact PBP mutant cells was $24 \%$, while the percentage of the intact wild-type cells was $4.6 \%$. The PBP mutant cells exhibited decreased cell-lysis profile. Therefore, the traditional culture-based assays were not sufficient to provide insights about the subpopulation of viable but non-culture cells. Consequently, we need more adequate tools to be able to comprehend and fight the antibiotic resistance of bacteria.
\end{abstract}

Keywords: penicillin-binding protein (PBP); microfluidics; antibiotics; M. smegmatis; single-cell resolution; microscopy

\section{Introduction}

Antibiotic resistance remains one of the biggest threats to global health in spite of being an old fight for humankind. Better prevention and control plans and effective strategies against antibiotic resistance are needed [1]. The World Health Organization (WHO) categorizes emergence and spread of antimicrobial resistance as a high priority action, and aims to ensure its prevention and treatment with effective and safe medicine while developing new antibiotics or alternative medicine to antibiotics [2,3]. Efficient strategies to manage antimicrobial resistance require a quantitative and deeper understanding of microbial behavior. Combining the qualities of different techniques will provide development of novel approaches for antibiotic-resistance problems. 
From Antonie van Leeuwenhoek to the 2000s, observation and investigation of microorganisms and development of antibiotics mostly relied on population-level assays, known as "bulk assays" [4]. The majority of the laboratories in academia, clinics, or pharmaceutical companies has continued to actively use these tools and methods. However, significant effort has been recently dedicated to increase the resolution of culture-based assays via the contributions of scientists from diverse disciplines, ranging from engineering, physics, statistics, medicine, and chemistry [5-8]. Our aim is to better understand microbial heterogeneity and antibiotic responses, not only during discrete physiochemical interactions at discrete-time points, but also to characterize their actions as dynamic, continuous time events while mimicking their pathophysiological conditions, such as microenvironments for biofilms [9]. Using microfabricated tools, scientists reported the importance of the microenvironment on motility, distribution and dynamics of bacterial culture [10-13]. In contrast to statically culturing cells in flasks, bacteria are cultured in microchannels, fed by a continuous medium flow where the antibiotic can be added into the medium, and the antibiotic response of the cells can be dynamically observed at single-cell resolution [10]. Therefore, these technologies have great potential for observing and quantifying the microenvironmental conditions that shape the survival strategies of bacteria, such as biofilms. Biofilms are strictly regulated by their surrounding microenvironments [14-16]; these might be able to be tightly controlled using microfluidic devices. Moreover, microfluidic cell culture systems have provided great potential for culturing currently viable but non-culturable bacteria (VBNCs) in laboratories, while discovering the mechanisms behind their phenotype [11]. Pioneering work by Dr. Austin and his co-workers has combined theoretical and experimental methods to unearth the cryptic complexity of bacterial evolution in studying the antibiotic response of the cells in dynamic, spatially heterogeneous microenvironments [17-19]. Dr. Ackermann and his group presented novel data about molecular microbial ecology using time-lapse microscopy and single-cell analysis [19-23]. From the fundamental side, these studies provide an ability to culture microbes in dynamic environments to reveal their role in the environment, ecology, and nutrient cycle. From the applied side, understanding of the underlying molecular mechanisms they develop to adapt to different stresses will be transferable to benefits for health, ecology and science. Uncovering the mystery of adaptation strategies to survive in the microbial word requires exploring bacteria in their complex, natural microenvironments; otherwise, impaired or underestimated results will mask their variability, and avoid conditions that cause antibiotic-resistant infections. Therefore, single-cell level and culture-based assays are complementary pieces of the current state-of-the-art.

In this study, we investigate the stress response of Mycobacterium smegmatis (M. smegmatis) transposon mutant, msm0031::Tn, using microfluidics and bulk assays. M. smegmatis is a rod-shaped bacterium with a complex cell wall [24,25]. It is a model organism for human pathogen, Mycobacterium tuberculosis (M. tuberculosis). However, it is a non-pathogen, fast-growing organism that requires a biosafety level 1 laboratory. It shares more than 2000 homologous genes with M. tuberculosis [26,27]. The product of the $m s m 0031$ gene is a penicillin-binding protein (PBP) required for cell division and involved in cell wall formation. The M. smegmatis msm0031::Tn mutant has remarkable isoniazid-killing phenotype both at population and single-cell levels.

PBPs are sets of membrane-bound enzymes, enrolled in glycan chain assembly and peptide cross-linking of bacterial peptidoglycan. The underlying beta-lactam resistance mechanism relies on modification of the PBPs in terms of copy number or affinity towards beta-lactams. Contribution of PBP mutations has been continuously investigated in various bacterial species regarding the development of tolerance to several antibiotics, including penicillin [28]. Here, we studied the influence of the PBP mutation on the isoniazid (INH)-killing kinetics of M. smegmatis using the method that was firstly reported by Wakamato et al. to show that the persistence of antibiotic stressed mycobacteria is dynamic [10]. Next, we used this approach to investigate the INH-killing profile of the NADH (reduced form of Nicotinamide adenine dinucleotide) pyrophosphate mutant of M. smegmatis [29]. Our findings reported that the NADH pyrophosphate mutant cells had a low level of cell division and a high level of cell lysis, and that they were incapable of regrowth upon INH removal. Contrary 
to our microfluidic-based approaches, in literature most mycobacterial studies have investigated PBPs using transposon mutants with specific phenotypes in batch culture [30]. Patru and Pavelka investigated the role of PonA2 and PonA3 in mycobacterial peptidoglycan biology. They reported that $\triangle$ PonA2 strains have decreased susceptibility to the beta-lactams ampicillin and ceftriaxone, increased susceptibility to rifampin (RIF), and no susceptibility difference for isoniazid (INH), ethambutol (EMB), vancomycin, or imipenem. $\triangle$ PonA3 strains did not affect the antibiotic susceptibility. PonA2 has a role in adaptation to survival and these cells have spherical morphology due to weakened cell wall integrity. Bansal et al. characterized putative DD-carboxypeptidase (DD-CPase) via cloning MSMEG_2433 gene in Escherichia coli (E.coli) and showed that MSMEG_2433 is both a DD-CPase and beta-lactamase [31]. Enany and co-workers presented the role of mycobacterial DNA-binding protein 1, which controls suppression of DNA synthesis, respiration, and fatty acid synthesis, and protection against reactive oxygen species, so prevents rapid cell death in the stationary phase and provides long-term survival of mycobacteria [32]. Moreover, Flores, Parsons and Pavelka performed transposon mutagenesis of the beta-lactamase mutants of M. tuberculosis and M. smegmatis and screened for cephalosporin and ceftriaxone hypersusceptible mutants. Their results provided unknown proteins that are involved in peptidoglycan biosynthesis, cell division, or other cell envelope processes [33]. Kieser et al. performed whole-genome transposon mutagenesis screens in $M$. tuberculosis deleted for PonA1, PonA2, and LdtB, major peptidoglycan enzymes. They verified that M. tuberculosis uses alternative pathways to produce peptidoglycan; either PonA1 or PonA2, which genetically interact with LdtB, is required for $M$. tuberculosis growth that also provides differential susceptibility to antibiotics [34].

To our knowledge, the msm0031::Tn mutant has not been studied in detail using both culture-based and microfluidic-microscopy-based assays. Our findings present the effect of the msm0031 gene in increased INH-susceptibility. Our single-cell analysis complements the data obtained from culture-based assays while challenging the definition of death for bacteria.

\section{Materials and Methods}

\subsection{Growth of the Cells}

M. smegmatis cells were grown in standard Middlebrook 7H9 medium (BD/Difco) containing $0.085 \% \mathrm{NaCl}, 0.5 \%$ albumin, $0.2 \%$ glucose, $0.5 \%$ glycerol, and $0.05 \%$ Tween- 80 at $37{ }^{\circ} \mathrm{C}$ with shaking at $200 \mathrm{rpm}$ [35]. Optical density of the cells (absorbance at $600 \mathrm{~nm}$ ) was measured to determine the growth of the cells via a spectrophotometer (Thermo Scientific biomate 5, Waltham, MA, USA).

\subsection{Antibiotic Responses}

Agar plates were prepared with $15 \mathrm{~g} / \mathrm{L}$ Bacto agar (Sigma-Aldrich, St. Louis, MO, USA) and $15.5 \mathrm{~g} / \mathrm{L}$ Luria Miller broth base (Sigma-Aldrich) in water. M. smegmatis cells were grown to OD 600 of $0.5-1$ and diluted to $\mathrm{OD}_{600}$ of 0.05 , corresponding to $\sim 10^{7} \mathrm{CFU} / \mathrm{mL}$, in fresh $7 \mathrm{H} 9$ medium. Serial 10-fold dilutions were made using $100-\mu \mathrm{L}$ cultures and $900-\mu \mathrm{L} 1$ X PBS- $0.025 \%$ Tween solutions in 5 -mL polypropylene tubes. Appropriate dilutions of $100 \mu \mathrm{L}$ were plated onto agar-based media to ensure that the serial dilutions would give at least one countable plate. Unless otherwise specified, antibiotics were used at the following concentrations: INH: $50 \mu \mathrm{g} / \mathrm{mL}, \mathrm{RIF}: 200 \mu \mathrm{g} / \mathrm{mL}, \mathrm{ETH}: 200$ $\mu \mathrm{g} / \mathrm{mL}, \mathrm{EMB}: 5 \mu \mathrm{g} / \mathrm{mL}$. Then, plates were incubated at $37^{\circ} \mathrm{C}$ and colonies were enumerated on day 4 .

\subsection{Environmental Stresses}

Sensitivity of the msm0031::Tn mutant and wild-type cells to thermal stress $\left(45^{\circ} \mathrm{C}\right)$, the detergent sodium dodecyl sulphate (0.1\%. SDS), acidic $\mathrm{pH}(\mathrm{pH} 4.5)$, and nutrient starvation by incubation of cells in phosphate-buffered saline (PBS) was determined [35]. 


\subsection{Minimum Inhibitory Concentration (MIC)}

M. smegmatis cells were grown to $\mathrm{OD}_{600}$ of $0.5-1$ and diluted to $\mathrm{OD}_{600}$ of 0.05 in fresh $7 \mathrm{H} 9$ medium. Then 10-fold serial dilutions were plated on Luria broth (LB) agar solid plates containing various concentrations of INH. MIC was defined as the lowest concentration of drug required seeing minimum bacterial colony-forming unit (CFU).

\subsection{Transposon (Tn) Mutagenesis and Identification of the msm0031::Tn Mutant}

The fMycoMarT7 transposon donor phagemid (provided by Eric Rubin, Harvard School of Public Health), which carries a selectable marker for kanamycin resistance, was used to mutagenize a strain of M. smegmatis mc $^{2} 155$ [32]. For identification of the msm0031::Tn mutant, genomic DNA was extracted using lysozyme, proteinase $\mathrm{K}$ digestion, cetrimide saline, and chloroform extraction [33]. Then, genomic DNA was digested with BamHI (New England BioLabs, NEB, Ipswich, MA, USA), the digested DNA was ligated with T4 ligase (NEB) and transformed into Pir1 competent E. coli cells (Invitrogen, Carlsbad, CA, USA). Kanamycin-resistant colonies were selected; plasmid DNA was isolated, and sequenced using the primer cttctgagcgggactctgggg (Supplementary Materials, Figures S1-S3) [29,36].

\subsection{Microfluidic Chip and Live-Cell Imaging}

The microfluidic chip provided growth of the cells between the coverslip (\#1) and the semipermeable membrane (Spectrum Lab, MWCO:8, Rancho Dominguez, CA, USA), which was under the Polydimethylsiloxane (PDMS, Sylgard 184) microfluidic channels with the same diameter (22 $\mathrm{mm}$ ) of the coverslip, Figure 1. The microfluidic network considered a series of parallel channels in between the inlet and outlet with a $50 \mu \mathrm{m} \times 50 \mu \mathrm{m}$ height and width [10]. Wakamato et al. presented the design and fabrication of the device [10]. Continuous medium flow $(25 \mu \mathrm{L} / \mathrm{min})$ was provided using standard, silicone tubing (ID: $0.076 \mathrm{~cm}$, OD: $0.165 \mathrm{~cm}$, HelixMark, Würselen, Germany) and a syringe pump (World Precision Instruments, Sarasota, FL, USA). Medium switching was very practical for on-chip drug exposures [10]. Thanks to our microfluidic network, the cells were sandwiched between the membrane and coverslip, and the microchannels were on top of the membrane; therefore, the depth of the microchannels did not introduce any problems, such as cell-to-cell overlapping or focusing of cells (Figure 1).

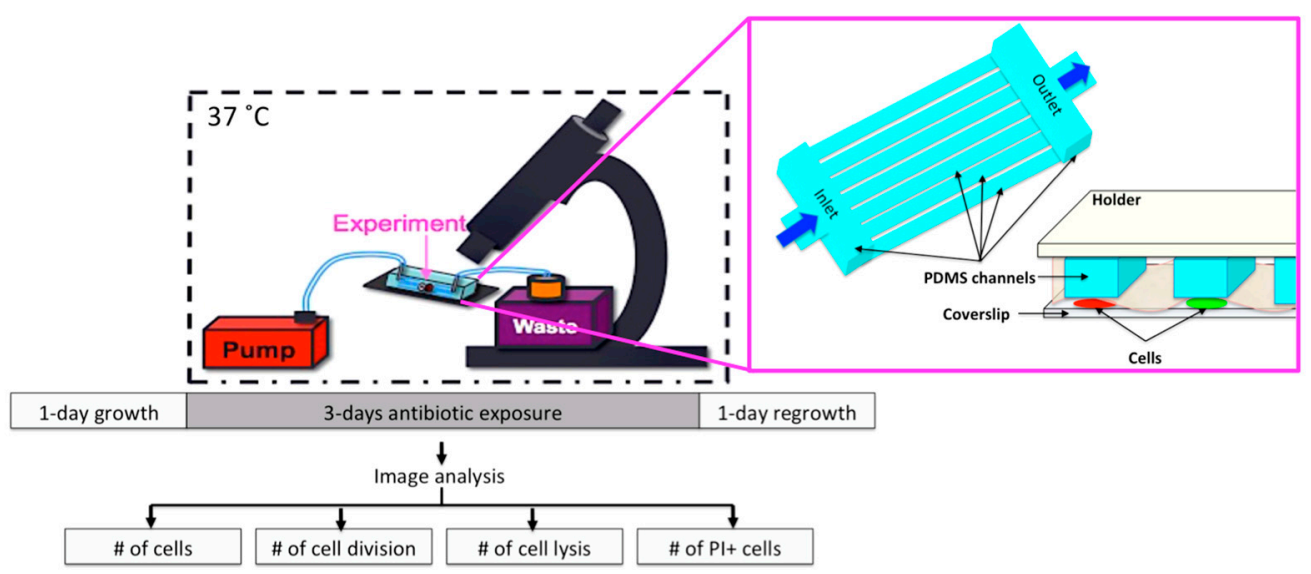

Figure 1. Schematics of the on-chip experiments and PDMS microfluidic device.

Moreover, the microfluidic device enabled the monitoring of single-cells during the pre-antibiotic, antibiotic, and post-antibiotic periods for $72 \mathrm{~h}$, which traditional methods cannot provide. Live-cell imaging was performed using an inverted, automated, time-lapse fluorescent microscope (Olympus IX75, Hamburg, Germany) equipped with a Hamamatsu ORCA-AG CCD camera. Using 100× oil-immersion objective (UPLFLN) images were acquired on phase and fluorescent channels (TRIS-red, 
GFP-green, exposure: $150 \mu \mathrm{s})$. The microfluidic device loaded with cells was mounted on the microscope inside a temperature-controlled chamber $\left(37^{\circ} \mathrm{C}\right)$.

\subsection{Image Analysis}

Time-lapse fluorescent movies were analyzed using cell counter plugin in ImageJ. The numbers of lysis and division events were manually counted using the cell counter plugin for every 4-h time frame. When the cells lysed, they lost their fluorescence. When the cells divided, their siblings appeared and expressed fluorescence.

In order to ensure the division and lysis events, the movies, obtained via merging the fluorescence and phase contrast images, were analyzed. The figures were plotted in Prism4.

\subsection{Statistical Analysis}

The Student's unpaired $t$-test (two-tailed) was used to assess statistical significance of pairwise comparisons. $p$-values were calculated using online software, GraphPad QuickCalcs. $p$-values $<0.05$ present statistically significant differences. Three independent experiments were performed and used to determine the $p$-values.

\section{Results}

\subsection{Batch-Cultue Behavior of the msm0031 Transposon Mutant and Wild-Type M. smegmatis Cells}

Growth and stress responses of the cells, particularly to antibiotics, was conducted using population-level, batch-culture assays.

Growth was determined by monitoring optical absorbance of the msm0031 transposon mutant and wild-type (WT) cells in standard 7H9 medium. The msm0031 transposon mutant was capable of growth with WT kinetics (Figure 2; Supplementary Materials, Figures S4 and S6).

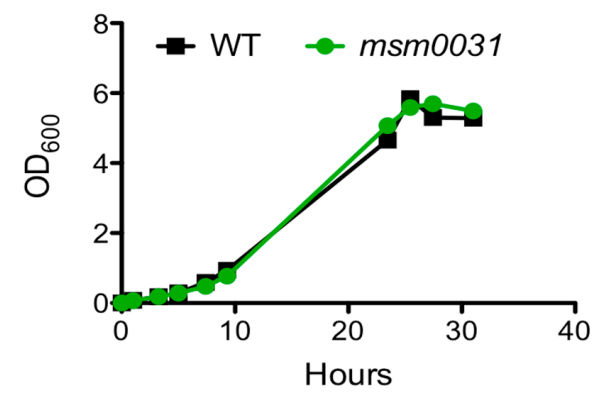

Figure 2. Growth of the msm0031::Tn mutant and wild-type (WT) M. smegmatis cells in batch culture.

\subsection{Drug Specificity}

The impact of msm0031 transposon insertion on drug-mediated killing was determined for INH, ETH, EMB, and RIF, Figure 3.

Since the influence of INH for the PBP mutant was investigated, the MIC value of the msm0031 transposon mutant for INH was determined as $3.125 \mu \mathrm{g} / \mathrm{mL}$. The INH-MIC value of the wild-type M. smegmatis cells was measured as $3.125 \mu \mathrm{g} / \mathrm{mL}$.

The drug specificity of the msm0031 transposon mutant was tested to determine whether the mutant is phenotypically tolerant to a wide range of antibiotics (Supplementary Materials, Figures S5-S7). Comparison of persistence phenotype rates was defined as the fractional survival ratio (FSR). The FSR values were calculated as percentage survival of mutant cells divided by percentage survival of wild-type cells after $48 \mathrm{~h}$ of exposure to INH, RIF, ETH, and EMB [32]. FSR $>1$ persisted better than WT; FSR $<1$ showed decreased persistence compared to wild-type. $p$-values were calculated using the Student's unpaired $t$-test. $p$-values $<0.05$ were statistically significant. Mean values and standard errors were calculated from data obtained in three independent experiments (Table 1). 

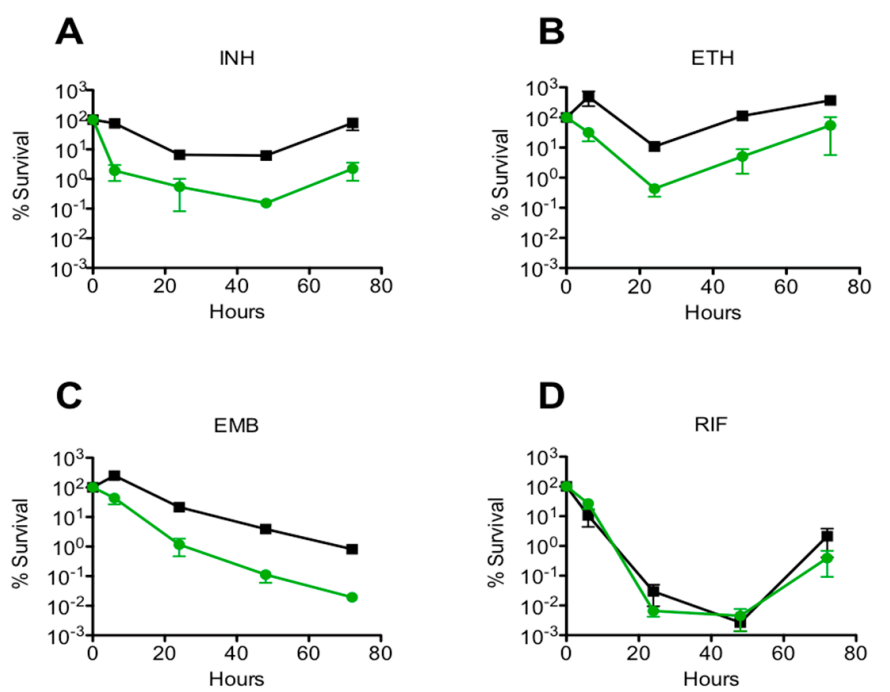

Figure 3. Batch culture drug-killing assay for the msm0031 transposon mutant (green circles) and wild-type M. smegmatis cells (black squares). (A) INH, $50 \mu \mathrm{g} / \mathrm{mL}$; (B) ETH, $200 \mu \mathrm{g} / \mathrm{mL}$; (C) EMB, $5 \mu \mathrm{g} / \mathrm{mL}$; and, (D) RIF, $200 \mu \mathrm{g} / \mathrm{mL}$. Results are the means and standard errors from 3 independent experiments.

Table 1. Fractional survival ratio (FSR) for the msm0031 transposon mutant and wild-type M. smegmatis cells $\left({ }^{* *} p<0.0001,{ }^{* *} p<0.01, * p<0.05\right)$.

\begin{tabular}{ccc}
\hline Antibiotics & FSR \pm SE WT & FSR \pm SE msm0031 \\
\hline INH $(50 \mu \mathrm{g} / \mathrm{mL})$ & $1 \pm 0.160$ & $0.024 \pm 0.040^{* * *}$ \\
EMB $(5 \mu \mathrm{g} / \mathrm{mL})$ & $1 \pm 0.630$ & $0.028 \pm 0.050^{* *}$ \\
RIF $(200 \mu \mathrm{g} / \mathrm{mL})$ & $1 \pm 0.001$ & $1.670 \pm 0.003$ \\
ETH $(200 \mu \mathrm{g} / \mathrm{mL})$ & $1 \pm 3.000$ & $0.040 \pm 3.700^{*}$ \\
\hline
\end{tabular}

\subsection{Stress Responses}

The responses of the msm0031::Tn mutant to other external stresses, including thermal stress (elevated temperatures of $\left.45{ }^{\circ} \mathrm{C}\right)$, detergent stress $(0.1 \%$ sodium dodecyl sulfate), acid stress ( $\mathrm{pH} 4.5)$, and nutrient starvation (incubation in phosphate-buffered saline, PBS 1X), were investigated (Figure 4) [37].
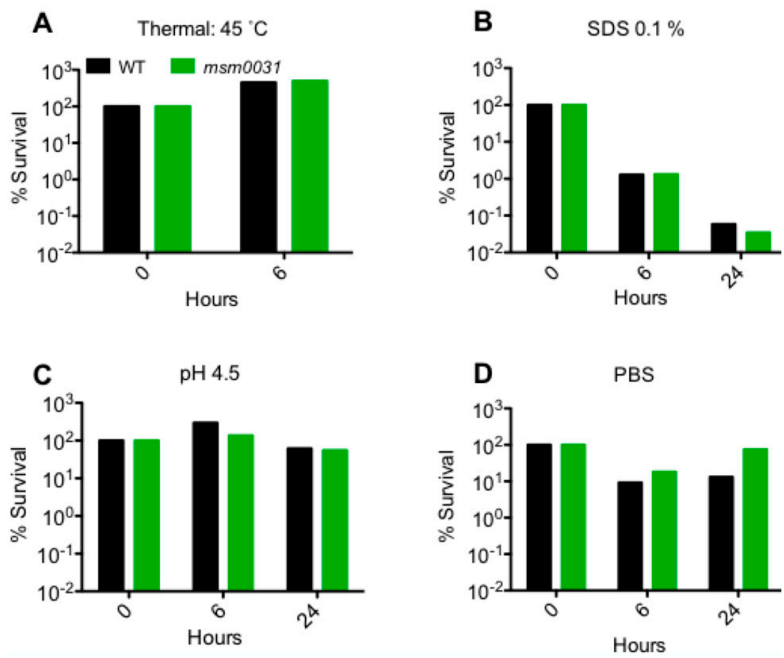

Figure 4. Sensitivity of the msm0031::Tn mutant and wild-type M. smegmatis cells to (A) $45^{\circ} \mathrm{C}$; (B) $0.1 \%$ sodium dodecyl sulfate; (C) $\mathrm{pH} 4.5$; and, (D) PBS (1X). 


\subsection{On-Chip Behavior of the msm0031 Transposon Mutant and Wild-Type M. smegmatis Cells}

On-chip experiments allowed us to simultaneously observe single cells in a mixture of both wild-type cells (green fluorescent) and the $m s m 0031$ transposon mutant cells (red fluorescent) while excluding the possibility that differences in the growth environment might be the cause of the observed phenotypes in previous assays (Supplementary Materials, Figure S4). Figure 1 illustrates how on-chip experiments were conducted and image analysis was performed.

The on-chip INH-killing experiment consisted of three steps: growth of the cells in standard 7H9 medium; three-day INH exposure for differential killing; and drug withdrawal to observe recovery from the antibiotic treatment [29]. Observation of the cells was achieved using live-cell imaging on the fluorescent microscopy (Supplementary Movie). Figure 5 demonstrates the on-chip behavior of the msm0031::Tn mutant and wild-type cells at single-cell resolution.
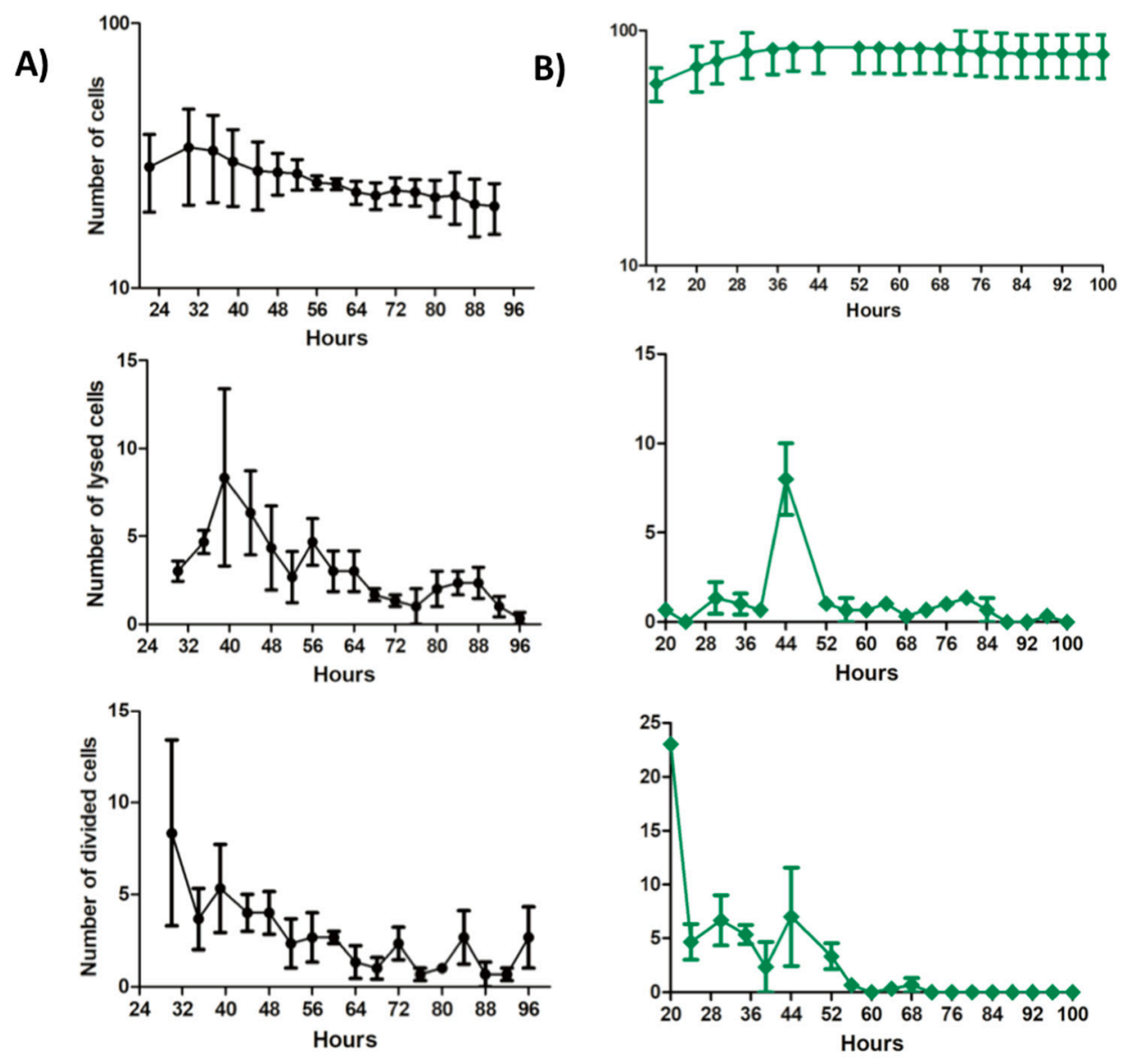

Figure 5. Quantitative single-cell analysis using on-chip-microscopy images of wild-type M. smegmatis (A) and the $m s m 0031:: T n$ mutant (B) during $72 \mathrm{~h}$ of INH $(50 \mu \mathrm{g} / \mathrm{mL})$ exposure. The first panel illustrates the cumulative behaviour of the cells as a composite of lysis and division events. The second panel shows the number of cells that lysed during each successive time interval. The third panel presents the number of cells that divided in each successive time interval. The data present the mean and standard errors of three points in the microfluidic device.

After drug withdrawal, an end-point staining was performed with propidium iodide (PI). In order to quantify the PI-positive, PI-negative and regrowth subpopulations of the cells, we used wild-type cells expressing green fluorescent protein, $m s m 0031$ transposon mutant cells expressing no flouresecent protein, and PI (red dye). For M. smegmatis wild-type cells, the number of intact cells following INH exposure was 512; 417 of these were PI-positive, 24 were PI-negative, one cell lysed, and 70 resumed growth after INH washout. Regarding the M. smegmatis msm0031::Tn mutant, the number of intact 
cells following INH exposure was 795; 605 of these were PI-positive, 190 were PI-negative, 4 resumed growth, and none of the cells lysed after INH washout. Figure 6 shows the comparison of WT and the msm0031 transposon mutant behavior at ten different points in the microfluidic device.

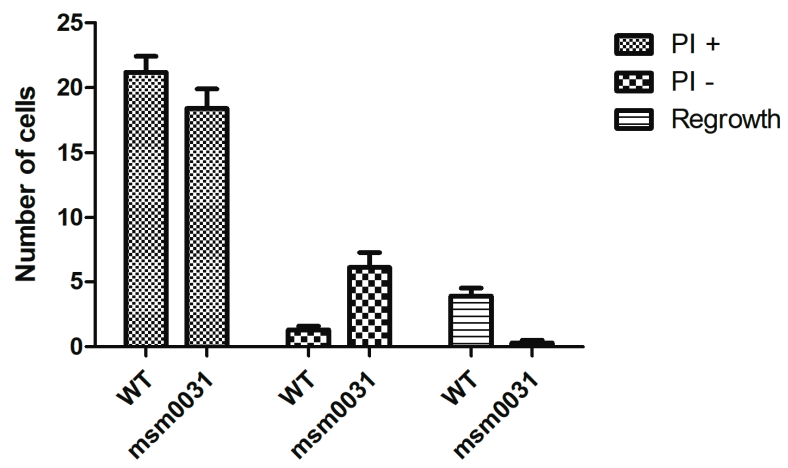

Figure 6. Phenotypic subpopulations of INH-exposed M. smegmatis wild-type and the msm0031::Tn mutant cells. The mean values show the number of cells, the error bars show the standard errors of ten different points in the microfluidic device. PI stands for propidium iodide staining. PI +: PI stained cells, PI-: PI-free cells.

\section{Discussion}

This work presented the behaviour of M. smegmatis msm0031 transposon mutant and wild-type cells both at single-cell level in conjunction with a microfluidic-microscopy system and at population-level using traditional, batch-culture assays. Since INH targets the mycobacterial envelope [29] and the msm0031 gene is a PBP involved in cell wall formation and cell division [28-31], our investigations mainly focused on the INH-killing profile of the M. smegmatis msm0031 transposon mutant.

In our studies, we obtained the M. smegmatis msm0031 mutant using transposon mutagenesis, which is one of the common genetic tools to obtain the specific mycobacterium phenotypes [33,34]. In literature, most of the PBP-related studies were performed using culture-based assays. These studies mainly focused on either antibiotic action mechanisms or bacterial peptidoglycan biosynthesis concepts. For the first concept, the antibiotic-killing profile of the PBP mutants was mostly questioned to understand how beta-lactam antibiotics work and how mycobacteria develops resistance to beta-lactams, such as penicillin [28], ampicillin, ceftriaxone [30], vancomycin, imipenem [31], cephalosporin, and ceftriaxone [32]. Among these studies, only Pature and Pavelka's research focused on INH susceptibility of the $\triangle$ PonA2 strains in addition to beta-lactams while studying the role of the PonA2 and PonA3 genes in mycobacterial peptidoglycan formation [30]. The hypothesis of PBP enrollment in the cell envelope and cell division processes was mostly reported for the PonA1, PonA2 and LdtB proteins [33]. Next, they focused on purification and biochemical characterization of PBP proteins of mycobacterium. Patru and Pavelka's study reported the relationship between the spherical morphology of the cells and their antibiotic susceptibility via PBP proteins.

Here, we implemented single-cell level, microfluidic-microscopy and population-level, culture-based assays to investigate M. smegmatis transposon mutant, msm0031. First, we confirmed that there was no growth phenotype for the msm0031 transposon mutant. Next, we obtained the msm0031 deletion mutant. The msm0031 deletion strain presented hindered growth, defective cell separation, higher transcript levels and a cell area twice as large compared to wild-type cells (Supplementary Materials, Figures S3-S5). Then, we performed batch-culture drug susceptibility assays using INH, ETH, EMB, and RIF [38]. Among them, RIF killed both the PBP mutant and wild type cells until $48 \mathrm{~h}$; afterwards, rifampicin degraded and the cells regrew (Figure 3) [39-41]. The PBP mutant presented enhanced killing profile for INH, ETH, and EMB; these drugs targets cell wall components (Figure 3, Table 1). In addition, we determined the sensitivity of the msm0031 transposon mutant 
to thermal stress, detergent, acidic $\mathrm{pH}$, and nutrient starvations to confirm the INH-killing profile of the msm0031 transposon mutant was not mainly due to impaired cell wall formation (Figure 4). Moreover, the drug-specificity assays were performed for the $\Delta m s m 0031$ deletion strain. The deletion strain exhibited similar killing patterns to the transposon mutant (Supplementary Materials, Figure S5). When we complemented both the transposon mutant and deletion strain, we could not retain the wild-type phenotype (Supplementary Materials, Figures S2, S6 and S7).

Next, we observed and quantified INH-killing kinetics of the msm0031 transposon mutant and wild-type cells at micro scale using a microfluidic device. The main advantages of using a microfluidic-microscopy system in our experiments were the ability to track single cells from pre-antibiotic to post-antibiotic periods, to perfuse continuous medium and drug (which excluded drug degradation and waste accumulation), and to quantify morphology, lysis and division of the cells in real-time. Our microfluidic assays showed that our hypothesis based on bulk assays, which was that enhanced INH-killing of the msm0031 transposon mutant was due to elevated lysis of the cells in the presence of INH, was wrong. The msm0031 transposon mutant formed fewer colonies on standard LB plates compared to wild-type cells during the INH exposure in the batch culture. Therefore, as a consequence of the microfluidic assay, our prediction was increased cell lysis and a decreased number of intact cells for the msm0031 transposon mutant. However, quantitative single-cell analysis presented contradictory results. It showed that upon INH-treatment, 24\% of the PBP mutant cells were intact and PI negative, whereas this subpopulation was only $4.6 \%$ of the wild-type cells. In addition, both the division and lysis kinetics of the PBP transposon mutant and wild-type cells were quite different (Figure 5). The killing events of the PBP mutant between $40-48 \mathrm{~h}$ might be due to the tolerance of the cell wall, which cannot balance the osmatic pressure and, hence, most of the cells burst. Actually, the batch culture-killing curve also shows rapid killing around 30-48 h, as shown in Figure 3. The wild-type cells lysed more than the PBP transposon mutant and its cumulative lysis was more than its cumulative division. Hence, the wild-type cells were rapidly killed after $12 \mathrm{~h}$ of drug exposure in the microfluidic assay $(32 \mathrm{~h})$, which is also consistent with the batch-culture INH-killing profile. On the other hand, the msm0031 transposon mutant actively divided up to $52 \mathrm{~h}$ and almost stopped its division at $60 \mathrm{~h}$. Furthermore, it lysed less than wild-type cells. Finally, when we removed INH, $13.7 \%$ of the wild-type cells and $0.5 \%$ of the PBP mutant cells resumed growth. The subpopulation of the PBP mutant, which cannot form colonies, recovered growth but remained intact and PI-negative. It might be viable and non-culturable cell populations that could actively grow when specific culturing conditions were provided. The msm0031 transposon mutant cells have always followed the same trends for the INH-killing profile, although the maximum lysis of the PBP mutant cells has varied within the $30-48 \mathrm{~h}$ of INH exposure.

The possible explanation for impaired colony formation and enhanced killing rate of the msm0031::Tn mutant could be explained by $\mathrm{PbpA}$, since PbpA enrols at the final stage of the peptidoglycan synthesis. Another possible explanation might be that the msm0031 gene is a part of a conserved gene cluster that is involved in coordinated regulation of cell division and/or cell elongation, and that interruption of any of these genes alters phenotypes of the cells (Supplementary Materials, Figures S1-S3).

To the best of our knowledge, our study is one of the first that combines culture-based assay results with on-chip-microscopy assays in regards to the drug killing aspects of the M. smegmatis transposon mutant, msm0031. In order to advance our knowledge about mechanisms of drug actions and functions of genes, we could incorporate the results obtained using different techniques at different scales, such as culture-based, population-level and microfluidic-microscopy-based, single-cell level assays. The results we obtained are the missing pieces of the puzzle of understanding how individuality of cells plays a role in the antibiotic response of the population, especially regarding the phenomenon of natural antibiotic resistance. 
Supplementary Materials: The following are available online at http:/ / www.mdpi.com/2072-666X/9/11/561/ s1. Figure S1: mRNA expressions for M. smegmatis msm0031 transposon mutant. Bars represent the ratio of mRNA levels relative to sigA, a constitutive gene whose expression remains relatively unchanged. Number of transcript copies determined by qRT-PCR using gene-specific primers as listed below. Figure S2: Chromosomal locus encoding the msm0031 gene in M. smegmatis. Location of the transposon insertion indicated by vertical arrow. Figure S3: Confirmation for the msm0031 deletion mutant measuring the mRNA expression levels. Bars represent the ratio of mRNA levels relative to sigA, a constitutive gene whose expression remains relatively unchanged. Number of transcript copies determined by qRT-PCR using gene specific primers as listed in materials and methods. The RT-qPCR experiments were performed at least 2 times. Figure S4: Deletion of msm0031 gene altered morphology and growth rate. Deletion of msm0031 gene affected colony morphology (A), limited growth in standard 7H9 broth (B). Bright field images showed PBPA-inactivated cells were longer (C). Fluorescence microscopy of msm0031 deletion mutant transformed with Wag31-GFP showed defective septum formation in the presence of INH (D). Using time-lapse movies generation time was calculated as 3 hours for the msm0031 deletion cells (E). The measured cell area for the msm0031 deletion strain was 2 times larger than WT (F). Figure S5: Batch culture drug-killing assays for the msm0031 deletion mutant. WT M. smegmatis and the msm0031 deletion mutant were treated with INH-50 $\mu \mathrm{g} / \mathrm{mL}$ (A), ETH-200 $\mu \mathrm{g} / \mathrm{mL}$ (B), EMB-5 $\mu \mathrm{g} / \mathrm{mL}$ (C), and RIF-200 $\mu \mathrm{g} / \mathrm{mL}$ (D). Serial dilutions of cultures were plated at the indicated time points to determine the CFU count. INH and EMB results are the mean \pm standard error from 3 independent cultures; ETH and RIF results are the mean \pm standard error from 3 independent cultures. Figure S6: Growth curves for the complemented msm0031 transposon and deletion strains. Growth was monitored by measuring culture turbidity $\left(\mathrm{OD}_{600} \mathrm{~nm}\right)$ at the indicated time points. Figure S7: Batch culture drug-killing assays for the complemented msm0031 deletion and transposon strains. WT $M$. smegmatis, the complemented msm0031 deletion and complemented msm0031 transposon mutant were treated with INH-50 $\mu \mathrm{g} / \mathrm{mL}$ (A), ETH-200 $\mu \mathrm{g} / \mathrm{mL},(B)$, EMB-5 $\mu \mathrm{g} / \mathrm{mL}$ (C), and RIF-200 $\mu \mathrm{g} / \mathrm{mL}$ (D). Serial dilutions of cultures were plated at the indicated time points to determine the Log CFU. The results are representatives at least two independent experiments. Video S1: PBP mutant.

Funding: This research is funded by EPFL.

Acknowledgments: This work was performed in the McKinney Lab at EPFL. This work gratefully acknowledges kind support from John D. McKinney and Neeraj Dhar.

Conflicts of Interest: There are no conflicts to declare.

\section{References}

1. Schneider, E.K.; Reyes-Ortega, F.; Velkov, T.; Li, J. Antibiotic-non-antibiotic combinations for combating extremely drug-resistant Gram-negative 'superbugs'. Essays Biochem. 2017, 61, 115-125. [CrossRef] [PubMed]

2. WHO. WHO GAP AMR Newsletter; The World Health Organization (WHO): Geneve, Switzerland, 2017; Volume 27.

3. Maltezu, H.C.; Theodoriduo, M.; Daikos, G.L. Antimicrobial resistance and the current refugee crisis. J. Glob. Antimicrob. Resist. 2017, 10, 75-79. [CrossRef] [PubMed]

4. Dhar, N.; McKinney, J.D. Microbial phenotypic heterogeneity and antibiotic tolerance. Curr. Opin. Microbiol. 2007, 10, 30-38. [CrossRef] [PubMed]

5. Weibel, D.B.; DiLuzio, W.L.; Whitesides, G.M. Microfabrication meets microbiology. Nat. Rev. Microbiol. 2007, 5, 209-218. [CrossRef] [PubMed]

6. Rusconi, R.; Garren, M.; Stocker, R. Microfluidics expanding the frontiers of microbial ecology. Annu. Rev. Biophys. 2014, 43, 65-91. [CrossRef] [PubMed]

7. Yawata, Y.; Nguyen, J.; Stocker, R.; Rusconi, R. Microfluidic Studies of Biofilm Formation in Dynamic Environments. J. Bacteriol. 2016, 198, 2589-2595. [CrossRef] [PubMed]

8. Roggo, C.; van der Meer, J.R. Miniaturized and integrated whole cell living bacterial sensors in field applicable autonomous devices. Curr. Opin. Biotechnol. 2017, 45, 24-33. [CrossRef] [PubMed]

9. Brehm-Stecher, B.F.; Johnson, E.A. Single-cell microbiology: Tools, technologies, and applications. Microbiol. Mol. Biol. Rev. 2004, 268, 538-599. [CrossRef] [PubMed]

10. Wakamato, Y.; Dhar, N.; Chait, R.; Schnieder, K.; Signorino-Gelo, F.; Liebler, S.; McKinney, J.D. Dynamic persistence of antibiotic-stressed mycobacteria. Science 2013, 339, 91-95. [CrossRef] [PubMed]

11. Stewart, E.J. Growing Unculturable Bacteria. J. Bacteriol. 2012, 194, 4151-4160. [CrossRef] [PubMed]

12. Gu, H.; Hou, S.; Yongyat, C.; De Tore, S.; Ren, D. Patterned Biofilm Formation Reveals a Mechanism for Structural Heterogeneity in Bacterial Biofilms. Langmuir 2013, 29, 11145-11153. [CrossRef] [PubMed]

13. Zhang, H.P.; Be'er, A.; Florin, E.-L.; Swinney, H.L. Collective motion and density fluctuations in bacterial colonies. Proc. Natl. Acad. Sci. USA 2010, 107, 13626-13630. [CrossRef] [PubMed]

14. Esteban, J.; García-Coca, M. Mycobacterium Biofilms. Front. Microbiol. 2017, 8, 2651. [CrossRef] [PubMed] 
15. Totani, T.; Nishiuchi, Y.; Tateishi, Y.; Yoshida, Y.; Kitanaka, H.; Niki, M.; Kaneko, Y.; Matsumoto, S. Effects of nutritional and ambient oxygen condition on biofilm formation in Mycobacterium avium subsp. hominissuis via altered glycolipid expression. Sci. Rep. 2017, 7, 41775. [CrossRef] [PubMed]

16. Lebeaux, D.; Chauhan, A.; Rendueles, O.; Beloin, C. From in vitro to in vivo models of bacterial biofilm-related infections. Pathogens 2013, 2, 288-356. [CrossRef] [PubMed]

17. Zhang, Q.; Lambert, G.; Liao, D.; Kim, H.; Robin, K.; Tung, C.-K.; Pourmand, N.; Austin, R.H. Acceleration of Emergence of Bacterial Antibiotic Resistance in Connected Microenvironments. Science 2011, 333, 1764-1767. [CrossRef] [PubMed]

18. Zhang, Q.; Bos, J.; Tarnopolskiy, G.; Sturm, J.G.; Kim, H.; Pourmand, N.; Austin, R.H. You cannot tell a book by looking at the cover: Cryptic complexity in bacterial evolution. Biomicrofluidics 2014, 9, 052004. [CrossRef] [PubMed]

19. Lambert, G.; Vyawahare, S.; Austin, R.H. Bacteria and game theory: The rise and fall of cooperation in spatially heterogeneous environments. Interface Focus 2014, 4, 20140029. [CrossRef] [PubMed]

20. Mathis, R.; Ackermann, M. Response of single bacterial cells to stress gives rise to complex history dependence at the population level. Proc. Natl. Acad. Sci. USA 2016, 113, 4224-4229. [CrossRef] [PubMed]

21. Mathis, R.; Ackermann, M. Asymmetric cellular memory in bacteria exposed to antibiotics. BMC Evolut. Biol. 2017, 17, 73. [CrossRef] [PubMed]

22. Schreiber, F.; Littmann, S.; Lavik, G.; Escrig, S.; Meiborn, A.; Kuypers, M.M.; Ackermann, M. Phenotypic heterogeneity driven by nutrient limitation promotes growth in fluctuating environments. Nat. Microbiol. 2016, 1, 16055. [CrossRef] [PubMed]

23. Hall, A.R.; Angst, D.C.; Schiessl, K.T.; Ackermann, M. Costs of antibiotic resistance-Separating trait effects and selective effects. Evol. Appl. 2015, 8, 261-272. [CrossRef] [PubMed]

24. Benoît, Z.; Chami, M.; Houssin, C.; Dubochet, J.; Griffiths, G.; Daffé, M. Direct visualization of the outer membrane of mycobacteria and corynebacteria in their native state. J. Bacteriol. 2008, 90, 5672-5680. [CrossRef]

25. Hoffmann, C.; Leis, A.; Niederweis, M.; Plitzko, J.M.; Engelhardt, H. Disclosure of the mycobacterial outer membrane: Cryo-electron tomography and vitreous sections reveal the lipid bilayer structure. Proc. Natl. Acad. Sci. USA 2008, 105, 3963-3967. [CrossRef] [PubMed]

26. Reyrat, J.M.; Kahn, D. Mycobacterium smegmatis: An absurd model for tuberculosis? Trends Microbiol. 2001, 9, 472-474. [CrossRef]

27. Tyai, J.S.; Sharma, D. Mycobacterium smegmatis and tuberculosis. Tends Microbiol. 2002, 10, 68-69. [CrossRef]

28. Haenni, M.; Moreillon, P. Fitness Cost and Impaired Survival in Penicillin-Resistant Streptococcus gordonii Isolates Selected in the Laboratory. Antimicrob. Agents Chemother. 2008, 52, 337-339. [CrossRef] [PubMed]

29. Elitas, M. Isoniazid Killing of Mycobacterium smegmatis NADH Pyrophosphatase Mutant at Single-Cell Level using Microfluidics and Time-Lapse Microscopy. Sci. Rep. 2017, 7, 10770. [CrossRef] [PubMed]

30. Patru, M.M.; Pavelka, M.S., Jr. A Role for the class a penicillin-binding protein PonA2 in the survival of Mycobacterium smegmatis under conditions of nonreplication. J. Bacteriol. 2010, 192, 3043-3054. [CrossRef] [PubMed]

31. Bansal, A.; Kar, D.; Murugan, R.A.; Mallick, S.; Dutta, M.; Pandey, S.D.; Chowdhury, C.; Gosh, A. A putative low-molecular mass (LMM) penicillin-binding protein (PBP) of Mycobacterium smegmatis exhibits prominent physiological characters of DD-Carboxypeptidase and beta-lactamase. Microbiology 2015, 161, 1081-1091. [CrossRef] [PubMed]

32. Enany, S.; Yoshida, Y.; Tateishi, Y.; Ozeki, Y.; Nishiyama, A.; Savitskaya, A.; Yamaguchi, T.; Ohara, Y.; Yamamoto, T.; Ato, M.; et al. Mycobacterial DNA-binding protein 1 is critical for long term survival of Mycobacterium smegmatis and simultaneously coordinates cellular functions. Sci. Rep. 2017, 7, 6810. [CrossRef] [PubMed]

33. Kieser, K.J.; Baranowski, C.; Chao, M.C.; Long, J.E.; Sassetti, C.M.; Waldor, M.K.; Sacchettini, J.C.; Ioerger, T.R.; Rubin, E.J. Peptidoglycan synthesis in Mycobacterium tuberculosis is organized into networks with varying drug susceptibility. Proc. Natl. Acad. Sci. USA 2015, 112, 13087-13092. [CrossRef] [PubMed]

34. Flores, A.R.; Parson, L.M.; Pavelka, M.S., Jr. Characterization of novel Mycobacterium tuberculosis and Mycobacterium smegmatis mutants hypersusceptible to beta-lactam antibiotics. J. Bacteriol. 2005, 187, 1892-1900. [CrossRef] [PubMed] 
35. Wendel, S.O.; Perera, A.S.; Pfromm, P.H.; Czermak, P.; Bossmann, S.H. Adaptation of Mycobacterium smegmatis to an industrial scale medium and isolation of the Mycobaterial PorinMspA. Open Microbiol. J. 2013, 7, 92-98. [CrossRef] [PubMed]

36. Belisle, J.T.; Sonnenberg, M.G. Isolation of genomic DNA from mycobacteria. Methods Mol. Biol. 1998, 101, 31-44. [CrossRef] [PubMed]

37. Gebhard, S.; Humpel, A.; McLellan, A.D.; Cook, G.M. The alternative sigma factor SigF of Mycobacterium smegmatis is required for survival of heat shock, acidic $\mathrm{pH}$ and oxidative stress. Microbiology 2008, 154, 2786-2795. [CrossRef] [PubMed]

38. Marrakchi, H.; Lanéelle, G.; Quémard, A. InhA, a target of the antituberculous drug isoniazid, is involved in a mycobacterial fatty acid elongation system, FAS-II. Microbiology 2000, 146, 289-296. [CrossRef] [PubMed]

39. Agrawal, S.; Panchagnula, R. In vitro analysis of rifampicin and its effect on quality control tests of rifampicin containing dosage forms. Pharmazie 2004, 59, 775-781. [PubMed]

40. Singh, S.; Mariappan, T.T.; Sharda, N.; Singh, B. Degradation of rifampicin, isoniazid and pyrazinamide from prepared mixtures and marketed single and combinational products under acid conditions. Pharm. Pharmacol. Commun. 2000, 6, 491-494. [CrossRef]

41. Quan, S.; Venter, H.; Dabbs, E.R. Ribosylative inactivation of rifampin by Mycobacterium Smegmatis is a principal contributor to its low susceptibility to this antibiotic. Antimicrob. Agents Chemother. 1997, 41, 2456-2460. [CrossRef] [PubMed]

(C) 2018 by the author. Licensee MDPI, Basel, Switzerland. This article is an open access article distributed under the terms and conditions of the Creative Commons Attribution (CC BY) license (http://creativecommons.org/licenses/by/4.0/). 